\section{Commentary: Going with the flow-but do we have to be careful of the rapids downstream?}

\author{
Heidi B. Nafda, MD, and Eugene A. Grossi, MD
}

The techniques and surgical confidence in mitral valve repair have expanded drastically since Carpentier's presentation of the French Correction in 1983. ${ }^{1}$ Mitral rings, bands, neochords, and various leaflet procedures allow for excellent functional valve repair, being the preferred option for patients with severe primary regurgitation being cared for in centers with high technical success. ${ }^{2}$ This success is usually defined as achieving a repair with mild-to-no residual regurgitation, no stenosis, and long-term freedom from reintervention. In their interesting paper, Morichi and colleagues ${ }^{3}$ offer a nuanced assessment of mitral repair success with a detailed analysis of intracavitary left ventricular flow dynamics in patients who underwent various repair techniques compared with healthy volunteers. Twenty healthy volunteers, 9 patients with partial rings, and 5 patients with complete rings underwent 4-dimensional flow magnetic resonance imaging to visualize left ventricular and aortic flow patterns and calculate the energy loss from turbulent flow.

The use of 4-dimensional flow magnetic resonance imaging is helping elucidate the downstream effects of different cardiac lesions on cardiovascular disease pathology. For instance, in aortic stenosis, the development of aortopathy may be inferred from flow studies. ${ }^{4}$ Although the utility to an individual patient may not always be apparent, a better understanding of the hemodynamic pathology of cardiovascular disease may help us know when and how to intervene. In this early, exploratory study, the authors demonstrate difference in intraventricular flow patterns and energy loss

From the Department of Cardiothoracic Surgery, NYU Langone Health, New York, NY.

Disclosures: The authors reported no conflicts of interest.

The Journal policy requires editors and reviewers to disclose conflicts of interest and to decline handling or reviewing manuscripts for which they may have a conflict of interest. The editors and reviewers of this article have no conflicts of interest.

Received for publication May 4, 2020; revisions received May 4, 2020; accepted for publication May 4, 2020; available ahead of print May 15, 2020.

Address for reprints: Eugene A. Grossi, MD, Department of Cardiothoracic Surgery, NYU Langone Health, 530 First Ave, Suite 9V, New York, NY 10016 (E-mail:

Eugene.Grossi@nyulangone.org).

J Thorac Cardiovasc Surg 2022;163:960

$0022-5223 / \$ 36.00$

Copyright $($ C 2020 by The American Association for Thoracic Surgery

https://doi.org/10.1016/j.jtcvs.2020.05.015

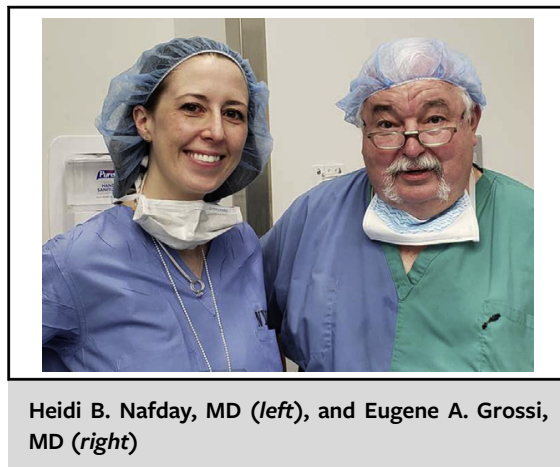

CENTRAL MESSAGE

4D-flow MRI offers a novel

approach to evaluating left ven-

tricular flow patterns and energy

loss after mitral valve repair, which may inform future deci-

sions about repair techniques.

with incomplete versus complete rings compared with healthy controls. At this time, it is not known whether these different postoperative flow vortices have meaningful effects on cardiac function or whether a subgroup of patients may have more vulnerability to those changes.

If the flow patterns demonstrated in patients who underwent mitral repair have significant clinical effects compared with control patients, might the functional approach to mitral valve repair need to be expanded? Should we not only create a functional valve but also achieve the bestpossible ventricular blood flow pattern to minimize energy loss? This seems like a lofty goal added onto the challenges of consistently producing successful mitral valve repairs. Nevertheless, as technology advances, the understanding of cardiovascular disease will expand with it, and individualized patient care with the best possible long-term outcomes will follow.

\section{References}

1. Carpentier A. Cardiac valve surgery-the "French correction" J Thorac Cardiovasc Surg. 1983;86:323-37.

2. Nishimura RA, Otto CM, Bonow RO, Carabello BA, Erwin JP 3rd, Guyton RA, et al. 2014 AHA/ACC guideline for the management of patients with valvular heart disease. J Am Coll Cardiol. 2014;63:e57-185.

3. Morichi H, Itatani K, Yamazaki S, Numata S, Nakaji K, Tamaki N, et al. Influences of mitral annuloplasty on left ventricular flow dynamics assessed with 3-dimensional cine phase-contrast flow magnetic resonance imaging. J Thorac Cardiovasc Surg. 2022;163:947-59.

4. Garcia J, Barker AJ, Markl M. The role of imaging of flow patterns by 4D MRI in aortic stenosis. JACC Cardiovasc Imaging. 2019;12:252-66. 